\title{
A fully human chimeric antigen receptor with potent activity against cancer cells but reduced risk for off-tumor toxicity
}

\author{
De-Gang Song ${ }^{1}$, Qunrui Ye ${ }^{1}$, Mathilde Poussin ${ }^{1}$, Lin Liu ${ }^{1}$, Mariangela Figini ${ }^{2}$, \\ Daniel J. Powell Jr ${ }^{1,3}$ \\ 1Ovarian Cancer Research Center, Department of Obstetrics and Gynecology, Perelman School of Medicine, University of \\ Pennsylvania, Philadelphia, PA, USA \\ ${ }^{2}$ Department of Experimental Oncology and Molecular Medicine, Fondazione IRCCS Istituto Nazionale dei Tumori, Milan, Italy \\ ${ }^{3}$ Department of Pathology and Laboratory Medicine, Abramson Cancer Center, Perelman School of Medicine, University of \\ Pennsylvania, Philadelphia, PA, USA
}

Correspondence to:

Daniel J. Powell Jr, e-mail: poda@mail.med.upenn.edu

Keywords: folate receptor alpha, chimeric antigen receptor, adoptive immunotherapy, ovarian cancer, T cells

Received: February 13, 2015

Accepted: June 08, 2015

Published: June 19, 2015

\section{ABSTRACT}

Chimeric antigen receptors (CARs) can redirect $T$ cells against antigen-expressing tumors in an HLA-independent manner. To date, various CARs have been constructed using mouse single chain antibody variable fragments (scFvs) of high affinity that are immunogenic in humans and have the potential to mediate "on-target" toxicity. Here, we developed and evaluated a fully human CAR comprised of the human C4 folate receptor-alpha (aFR)-specific ScFv coupled to intracellular $T$ cell signaling domains. Human T cells transduced to express the C4 CAR specifically secreted proinflammatory cytokine and exerted cytolytic functions when cultured with aFR-expressing tumors in vitro. Adoptive transfer of C4 CAR T cells mediated the regression of large, established human ovarian cancer in a xenogeneic mouse model. Relative to a murine MOv19 scFv-based aFR CAR, C4 CAR T cells mediated comparable cytotoxic tumor activity in vitro and in vivo but had lower affinity for aFR protein and exhibited reduced recognition of normal cells expressing low levels of aFR. Thus, $T$ cells expressing a fully human CAR of intermediate affinity can efficiently kill antigen-expressing tumors in vitro and in vivo and may overcome issues of transgene immunogenicity and "ontarget off-tumor" toxicity that plague trials utilizing CARs containing mouse-derived, high affinity scFvs.

\section{INTRODUCTION}

The adoptive transfer of $\mathrm{T}$ cells expressing chimeric antigen receptors (CARs), or "T bodies", has emerged as a powerful approach for cancer therapy [1]. CARs are comprised of an antigen-specific single-chain antibody variable fragment ( $\mathrm{scFv}$ ) fused to intracellular signaling domains derived from receptors involved in lymphocyte activation $[2,3]$. CARs can functionally redirect $\mathrm{T}$ cells with high specificity to various surface antigens on tumor cells independent of MHC restriction and antigen processing, and therefore bypass major mechanisms by which tumors escape immune recognition [3]. The effectiveness of CAR therapy is evidenced by the complete eradication of CD19-expressing hematological malignancies following the adoptive transfer of autologous T cells engineered to express a CD19 redirected CAR that is observed in multiple independent trials [4-8].

Folate receptor $\alpha(\alpha \mathrm{FR})$ is an attractive antigen for CAR-T cell therapy because $\alpha \mathrm{FR}$ expression is over expressed in approximately $90 \%$ of ovarian carcinomas $[9,10]$, as well as in cancers of the endometrium [10], kidney [10], breast [11], lung [12], pancreas [10], colorectal cancer [13] and mesothelioma [14], and its expression is not affected by prior administration of chemotherapy [15]. In normal organs, such as kidney, lung, breast, and salivary glands, $\alpha \mathrm{FR}$ expression is null or low and restricted to the apical surface of polarized epithelial cells [16], where it appears to be inaccessible to 
circulating anti- $\alpha \mathrm{FR}$ antibodies and folic acid conjugates. CAR-T cell therapy was first tested in ovarian cancer [17], where administration of $\mathrm{T}$ cells engineered to express an anti- $\alpha$ FR CAR composed of the murine MOv18 scFv and a CD3z endodomain was shown to be feasible but did not induce tumor regression due to the poor persistence of the gene-modified T cells. Moreover, a serum inhibitory factor, likely human anti-mouse antibodies (HAMA), was detected in the serum of patients following treatment and shown to dampen CAR T cell function [17]. Elsewhere, HAMA to murine scFv on CAR T cells has resulted in severe anaphylactic response under a delayed dosing regimen [18], further exemplifying the need for construction and testing of human $\mathrm{scFv}$ based CARs. We have recently demonstrated that incorporation of costimulatory signaling domains, such as CD137 (4-1BB), CD28 or CD27, into a $\alpha$ FR-specific CAR overcomes the limitations of past CAR approaches by improving the persistence and anti-tumor activity of transferred CAR $\mathrm{T}$ cells in vivo $[19,20]$. However, the anti- $\alpha \mathrm{FR} \mathrm{scFv}$ used in these studies was derived from the high affinity murine anti-human monoclonal antibody MOv19 and therefore runs the risk of being immunogenic in humans, and dampening the persistence and activity of $\alpha$ FR CAR $\mathrm{T}$ cells in vivo. The successful conversion of the murine MOv19 antibody to a fully human antibody, referred to as $\mathrm{C} 4$, through guided selection and chain shuffling techniques [21] makes the construction of a fully human anti- $\alpha$ FR CAR possible.

In this study, we constructed a novel fully human anti- $\alpha$ FR C4 CAR to reduce the risk of potential CAR transgene immunogenicity. The relative affinities of C4 and MOv19 in soluble scFv format has not been reported, however the binding affinity of the human $\mathrm{C} 4$ Fab fragment $\left(2 \times 10^{7} \mathrm{M}^{-1}\right)$ is approximately five-fold less than that of the high affinity murine MOv19 antibody. Even so, C4 retains its specificity for $\alpha \mathrm{FR}$ and its $\mathrm{K}(\mathrm{d})$ of $<10^{8} \mathrm{M}^{-1}$ is predicted to confer exclusive activation of CAR upon encounter with tumor cells bearing elevated amounts of surface $\alpha \mathrm{FR}$. The targeting domain is linked to a combined intracellular CD27 and CD3z signaling chain to further enhance the efficacy of this receptor (referred to hereafter as "C4-27z"). Here, we show that primary human $\mathrm{T}$ cells bearing the fully human $\mathrm{C} 4-27 \mathrm{z}$ CAR specifically react against $\alpha \mathrm{FR}^{\text {pos }}$ tumor cells in vitro, and mediate the regression of established human $\alpha \mathrm{FR}^{\text {pos }}$ tumor in xenogeneic mouse models of advanced subcutaneous or intraperitoneal ovarian cancer. In addition, $\mathrm{T}$ cells expressing the $\mathrm{C} 4-27 \mathrm{z}$ CAR possess antitumor activity in vitro and in vivo that is similar to that achieved using $\mathrm{T}$ cells expressing the murine MOv19-27z CAR. Importantly, the $\mathrm{C} 4-27 \mathrm{z}$ CAR has reduced activity against normal cells bearing low level antigen and may decrease the potential risk of on-antigen, off-tumor toxicity. These results provide the rationale for the clinical investigation of fully human C4 CAR T cell therapy for the safe and effective treatment of a wide spectrum of $\alpha \mathrm{FR}$-expressing malignancies.

\section{RESULTS}

\section{Construction and expression of fully human C4 CAR}

The fully human anti-human $\alpha$ FR-specific C4 Fab (referred to as C4) was previously described [21]. C4 CAR constructs comprised of a $\mathrm{C} 4 \mathrm{scFv}$ linked to a CD $8 \alpha$ hinge and transmembrane region, followed by a $\mathrm{CD} 3 \zeta$ signaling moiety alone $(\mathrm{C} 4-\mathrm{z})$ or in tandem with the CD27 intracellular signaling motif were generated $(\mathrm{C} 4-27 \mathrm{z}$; Figure 1A) using CAR backbones described previously [19]. A previously described anti-CD19 CAR containing CD27 with CD3 $\zeta$ signaling motifs in tandem (CD19$27 \mathrm{z}$ ) was used as an antigen-specificity control $[19,22]$. Primary human CD4+ or CD8+ T cells were efficiently transduced with recombinant lentiviral vectors to express C4 CAR with transduction efficiencies of about $50-80 \%$ (Figure 1B), and equilibrated to similar transduction efficiencies by adding untransduced(UNT) T cells for all functional assays.

\section{C4 CAR T cells specifically recognize $\alpha F^{\text {pos }}$ ovarian cancer cells}

To determine whether C4 CAR-modified human T cells were able to recognize $\alpha \mathrm{FR}^{\text {pos }}$ tumor cells, the C4$27 \mathrm{z}$ CAR-bearing $\mathrm{T}$ cells were cultured with tumor cells, and IFN- $\gamma$ and IL- 2 responses measured by ELISA. Since ovarian cancers and breast cancers frequently express $\alpha \mathrm{FR}$, a panel of established human ovarian cancer cell lines (SKOV3, A1847, OVCAR-5, OVCAR-3 and A2780) and breast cancer cell lines (SKBR3, MCF7, MDA-468 and MDA-231) that expressed surface $\alpha \mathrm{FR}$ at varying levels or not at all (C30) was assembled for functional assays. As shown in Figure 2A and in Supplementary Figure 1A, C4$27 \mathrm{z}$ CAR T cells produced significant amounts of IFN- $\gamma$ and IL-2 after coculture with all $\alpha \mathrm{FR}^{\text {pos }}$ cancer cell lines, but not when cultured with $\alpha \mathrm{FR}^{\text {neg }}$ cells, indicating that C4 CAR T cells functionally recognize $\alpha \mathrm{FR}^{\text {pos }}$ tumor cells. The amount of IFN- $\gamma$ secreted correlated with the level of surface $\alpha \mathrm{FR}$ expressed by tumor cells $\left(R^{2}=0.9876\right.$, Figure 2B). In contrast, UNT T cells did not show any significant response to stimulation with $\alpha \mathrm{FR}^{\text {pos }}$ tumor cells (Figure 2A).

To investigate whether C4 CAR T cells recognize primary ovarian cancer cells expressing $\alpha \mathrm{FR}$, we used cryopreserved primary ovarian cancer samples as targets. As shown in Figure $2 \mathrm{C}, \mathrm{CD} 45^{\text {neg }} \mathrm{EpCAM}^{+}$ primary tumor cells in all five independent samples tested express moderate to high level $\alpha \mathrm{FR}$ on cell surface. In co-culture experiments, C4-27z CAR T cells secreted substantial amounts of IFN- $\gamma$ denoting T-cell activation (Figure 2D). All samples were recognized by $\mathrm{C} 4-27 \mathrm{z}$ CAR $\mathrm{T}$ cells, though the amount of IFN- $\gamma$ secreted did not correlate with the level of surface $\alpha \mathrm{FR}$ expressed by primary tumor cells. This 
A

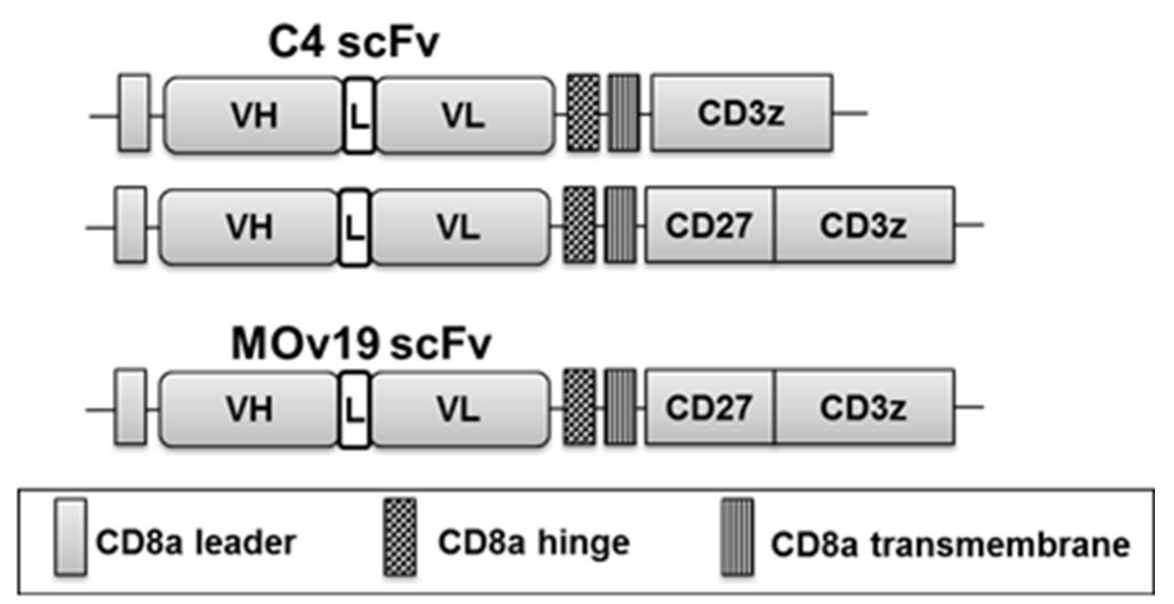

B

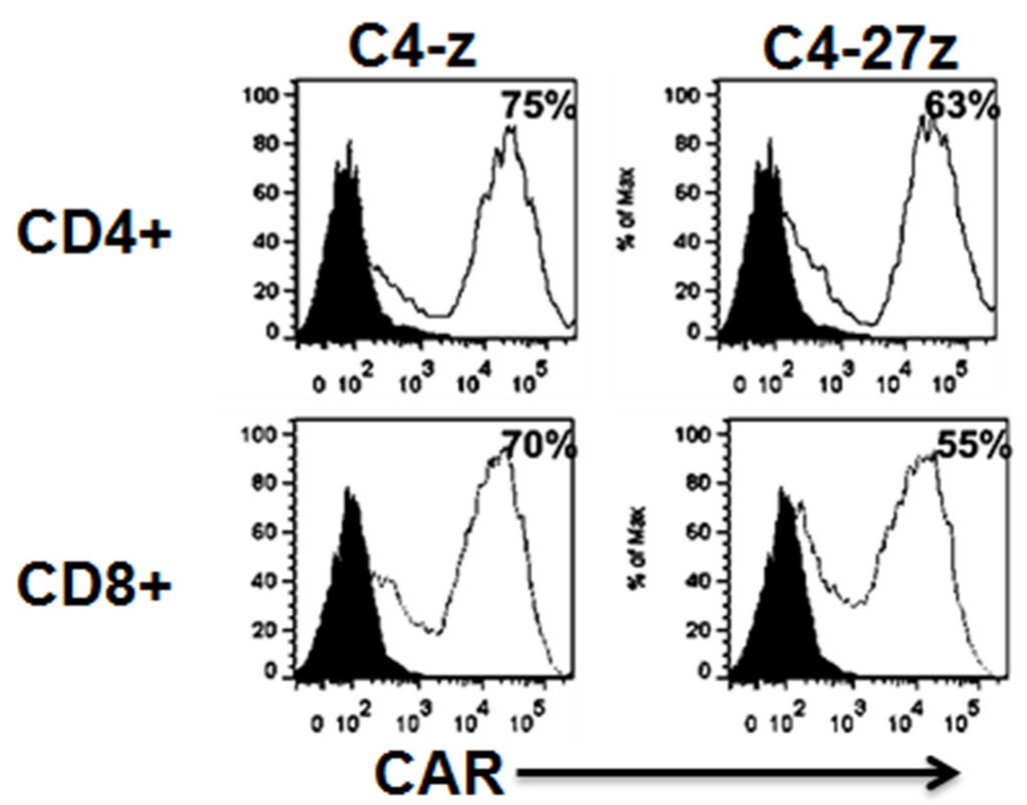

Figure 1: Generation of folate receptor alpha ( $\alpha \mathrm{FR})$-specific fully human chimeric antigen receptor (CAR) $T$ cells. A. Schematic representation of $\mathrm{C} 4$ based $\mathrm{CAR}$ constructs containing the $\mathrm{CD} 3 \zeta$ cytosolic domain alone (C4-z) or in combination with the CD27 costimulatory module (C4-27z). The murine anti-human $\alpha$ FR MOv19-27z CAR is also shown. B. Transduced T cells consisted of CD4and CD8-positive cells with both subsets expressing C4 CARs.C4 CAR expression (open histograms) was detected via biotin-labeled rabbit anti-human $\operatorname{IgG}(\mathrm{H}+\mathrm{L})$ staining followed by streptavidin-phycoerythrin after transduction with lentivirus compared to untransduced (UNT) $\mathrm{T}$ cells (filled blackhistograms). Transduction efficiencies are indicated with the percentage of CAR expression in parentheses. ScFv, singlechain antibody variable fragment; $\mathrm{L}$, linker; $\mathrm{C} 4$, anti- $\alpha \mathrm{FR}$ scFv; $\mathrm{VH}$, variable $\mathrm{H}$ chain; $\mathrm{VL}$, variable $\mathrm{L}$ chain; $\mathrm{TM}$, transmembrane region.

is likely attributed to the relatively similar levels of $\alpha \mathrm{FR}$ expressed among these difference biospecimens. No IFN- $\gamma$ production was detected when $\mathrm{C} 4 \mathrm{CAR}$ $\mathrm{T}$ cells were cultured with $\alpha \mathrm{FR}^{\text {neg }}$ targets (C30) or from cocultures with UNT $\mathrm{T}$ cells, ruling out the possibility that observed reactivity was a product of allo-recognition. Moreover, CD19 CAR T cells did not produce IFN- $\gamma$ when stimulated with primary $\alpha \mathrm{FR}^{\text {pos }}$ cancer cells (Figure 2D), illustrating the requirement for antigen specificity for CAR-T cell activity.
We recently demonstrated that tumor-reactive human $\mathrm{T}$ cells from patients with cancer express the costimulatory molecule CD137 (4-1BB) in an activation-induced manner allowing for the rapid identification of recently antigenactivated T cells ex vivo [23]. Following incubation of C4-27z CAR T cells or UNT T cells with $\alpha \mathrm{FR}^{\text {pos }}$ and $\alpha \mathrm{FR}^{\text {neg }}$ tumor cells, we found robust upregulation of CD137 expression by $\mathrm{T}$ cells only when $\mathrm{C} 4 \mathrm{CAR} \mathrm{T}$ cells were incubated with $\alpha \mathrm{FR}^{\text {pos }}$ tumor cells (Figure 2E). Notably, within C4 CAR T cell $/ \alpha \mathrm{FR}^{\text {pos }}$ tumor cell cocultures, CD137 expression was 
A

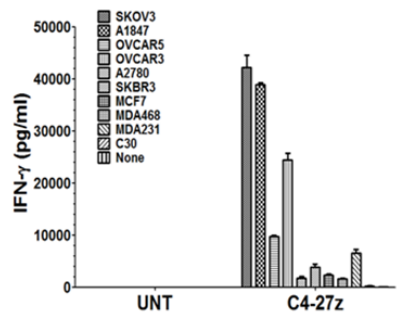

C

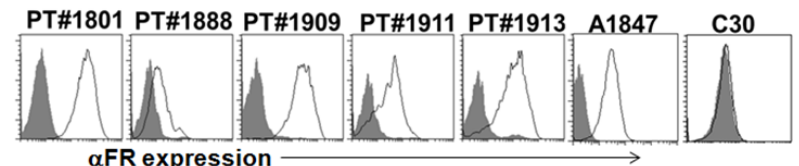

D

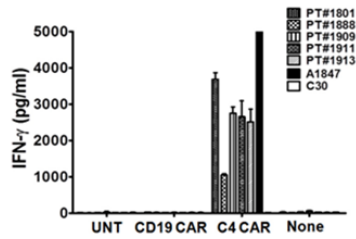

B

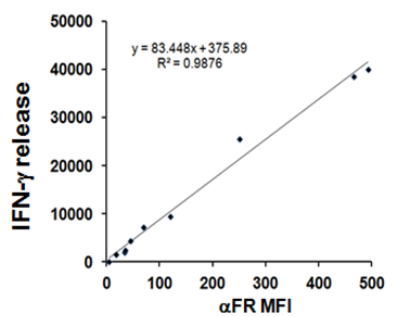

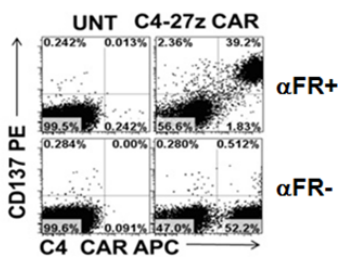

Figure 2: C4 CAR T cells secrete Th1 proinflammatory cytokine in response to tumor cell line and primary ovarian cancer cell surface associated $\boldsymbol{\alpha F R}$. A. C4-27z CAR but not UNT T cells $\left(10^{5}\right.$ cells/well) secret IFN- $\gamma$ following overnight incubation with ovarian and breast cancer cell lines $\left(10^{5}\right.$ cells/well) expressing different levels of surface $\alpha$ FR. Mean IFN- $\gamma$ concentration \pm SEM $(\mathrm{pg} / \mathrm{ml}$ ) from triplicate cultures is shown. B. Correlation between $\alpha \mathrm{FR}$ expression (mean fluorescence intensity; MFI) on tumor cells and the production of IFN- $\gamma$ by C4-27z CAR T cells cocultured with these tumor cells was plotted. C. Three primary ovarian cancer solid tumor samples (PT\#1909, 1911, and 1913) and two ascites samples (PT\#1801 and 1888) gated on CD45- EpCAM+ cells were stained with anti- $\alpha$ FR antibody (open histogram) or matched isotype controls (filled gray histogram) and analyzed by flow cytometry. A1847 and C30 cell lines served as $\alpha$ FR positive and negative expression controls, respectively. D. C4-27z CAR-modified T cells secrete IFN- $\gamma$ during overnight culture with CD45-depleted $\alpha \mathrm{FR}$-expressing primary human ovarian cancer samples and $\alpha \mathrm{FR}^{\mathrm{pos}}$ control cell line A1847, but not $\alpha \mathrm{FR}^{\mathrm{neg}} \mathrm{C} 30$ ovarian cancer cells. E. Antigen-specific T-cell induction of surface CD137 (4-1BB) expression was measured by FACS detection on C4-27z CAR T cells when stimulated overnight with $\alpha \mathrm{FR}+$ tumor cells (SKOV3, A1847 or T47D) but not $\alpha \mathrm{FR}^{\text {neg }}$ cells. UNT T cells did not upregulate CD137 expression. CD137 expression was preferentially increased on C4 CAR+ T-cell populations but not C4 CAR-T cells, after stimulation with $\alpha \mathrm{FR}^{\mathrm{pos}}$ tumor cells. Representative dotplots from flow-cytometric analysis of CAR T cells stimulated with SKOV3 $\alpha \mathrm{FR}^{\text {pos }}$ tumor cells are shown and results were similar using all $\alpha \mathrm{FR}^{\text {pos }}$ tumor cells tested.

restricted to human $\mathrm{T}$ cells bearing $\mathrm{C} 4 \mathrm{CAR}$ (Figure 2E). The CAR-negative $\mathrm{T}$ cell subset did not express CD137, confirming that $\mathrm{CD} 137$ upregulation was dependent upon specific antigen recognition by CAR T cells.

\section{C4 CAR T cells have anti-tumor activity in vitro and in vivo}

We next evaluated the cytolytic potential of $\alpha$ FR-specific C4 CAR-T cells in vitro in an overnight luminescence assay using firefly luciferase (fLuc + )expressing cancer cells as targets. C4-z and C4-27z CAR $\mathrm{T}$ cells specifically and efficiently lysed the $\alpha \mathrm{FR}^{\mathrm{pos}}$ human ovarian cancer cell lines SKOV3 (higher expression) and OVCAR5 (lower expression), but not $\alpha \mathrm{FR}^{\text {neg }} \mathrm{C} 30$ cells (Figure 3A) at effector to target ratios of 10:1 to 1:1. Control CD19 CAR T cells did not lyse ovarian cancer cells, which lack CD19.

To assess the antitumor activity of $\mathrm{C} 4 \mathrm{CAR}$ $\mathrm{T}$ cells against $\alpha \mathrm{FR}^{\mathrm{pos}}$ human tumor in vivo, we first evaluated their potency in a xenograft mouse model of subcutaneous ovarian cancer. Immunodeficient nonobese diabetic/severe combined immunodeficient/IL- $2 \gamma c^{\text {null }}$ (NSG) mice were inoculated subcutaneously with fLuc+ $\alpha \mathrm{FR}^{\mathrm{pos}}$ human ovarian cancer SKOV3 cells on the hind flank and received intravenous injection of $10^{7} \mathrm{CAR}+$ $\mathrm{T}$ cells on day 40 after tumor inoculation when tumors were $\sim 250 \mathrm{~mm}^{3}$ in size and evident by bioluminescence imaging. Intravenous administration of C4-27z CAR-T cells significantly delayed tumor progression compared to tumor growth observed in control mice treated with UNT $\mathrm{T}$ cells $(p=0.005)$. Furthermore, incorporation of CD27 signals enhances antitumor activity in vivo, because $\mathrm{C} 4$ $27 \mathrm{z}$ T cells therapy was superior to therapy with the firstgeneration C4-z CAR T cell $(p=0.015)$, which lacks a CD27 costimulation domain (Figure 3B, 3C).

Advanced ovarian cancer usually presents with widespread intra-abdominal metastasis, resulting in malignant ascites. A xenogeneic mouse model of advanced intraperitoneal (IP) metastatic cancer was established to evaluate the functional activity of C4-27z CAR T cells against tumor localized to a more physiologically relevant compartment. In this model, untreated mice develop multiple nodular peritoneal tumors and ascites, with tumors 
A
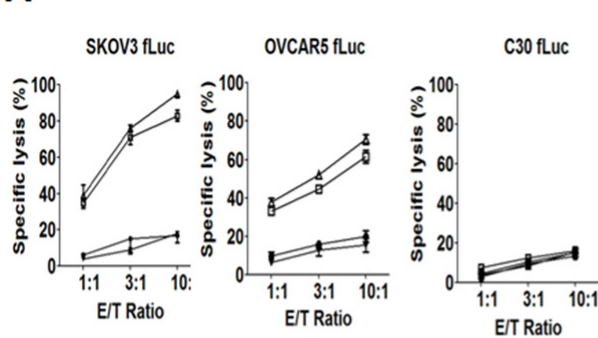

C

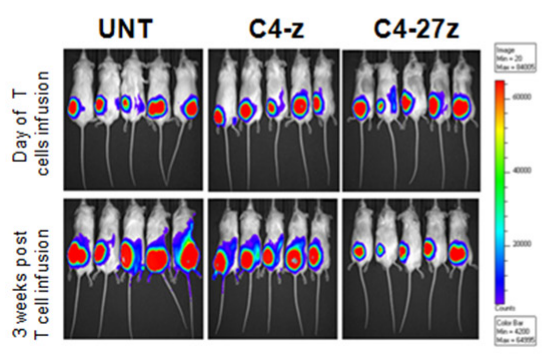

B

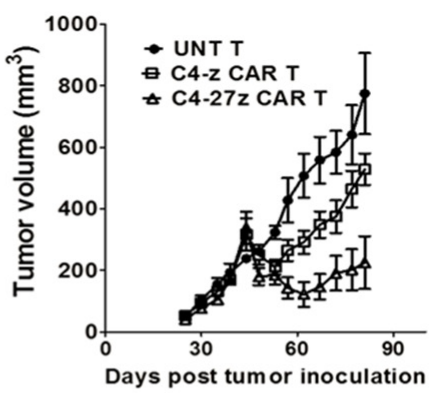

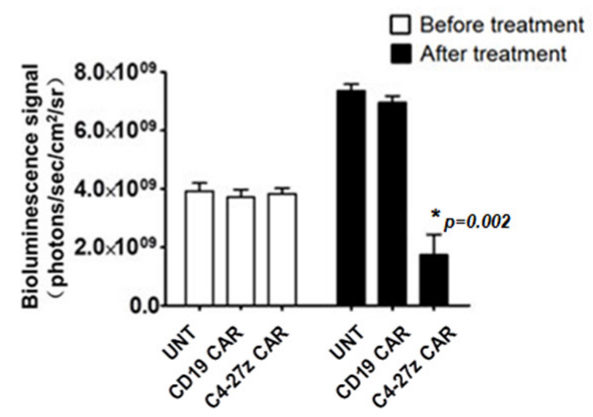

Figure 3: Antitumor activity of human T cells expressing C4 CAR in vitro and in vivo. A. Cytotoxicity of $\alpha \mathrm{FR}$-expressing tumor cells SKOV3 (higher expression) and OVCAR5 (lower expression) by CAR T cells in 18-hour bioluminescence assay at the indicated E/T ratio. UNT T cells and CD19-27z CAR T cells served as negative effector controls. C30 cells served as negative target cell control. Percent tumor cell viability was calculated as the mean luminescence of the experimental sample minus background divided by the mean luminescence of the input number of target cells used in the assay minus background times 100. All data are represented as a mean of triplicate wells. B. NSG mice bearing established s.c. tumor were treated with intravenous (i.v.) injections of $1 \times 10^{7} \mathrm{CAR}+\mathrm{T}$ cells on day 40 post tumor inoculation. Tumor growth was assessed by caliper measurement $\left[V=1 / 2\left(\right.\right.$ length $\times$ width $\left.\left.{ }^{2}\right)\right]$. C. Tumor progression was also followed by in vivo bioluminescence imaging. D. NSG mice received i.p. injection of $3 \times 10^{6} \mathrm{SKOV} 3 \mathrm{fLuc}$ tumor cells and were randomized into 3 groups of 5 mice each before beginning therapy with UNT T cells or T cells expressing C4-27z or CD19-27z CAR via i.v. infusion on day 21 and 25 after tumor inoculation. Photon emission from fLuc tumor cells was quantified and the mean \pm SD bioluminescence signal determined prior to and two weeks after second i.v. injection of $1 \times 10^{7}$ CAR-T cells on days 21 and 25 after tumor inoculation.

also found on the surfaces of the diaphragm, intestines uterus and associated fat, and stomach, requiring euthanasia approximately 40 days post-inoculation. We injected $3 \times$ $10^{6} \mathrm{fLuc}+\mathrm{SKOV} 3$ cells IP into NSG mice and followed tumor growth by bioluminescence imaging (BLI). After 3 weeks, mice received intravenous injections of $10^{7} \mathrm{C} 4$ $27 \mathrm{z}$ CAR + T cells given on day 21 and day 25 post tumor inoculation. Control groups of tumor-bearing mice were injected with untransduced or CD19-27z CAR T cells, and in these mice, the tumors grew rapidly, as measured by BLI (Supplementary Figure 1B). In contrast, there was a significant difference in tumor burden between $\mathrm{C} 4-27 \mathrm{z}$ CAR $\mathrm{T}$ cells and control T-cell groups 14 days after second T-cell dose injection ( $p=0.002$; Figure 3D). CD27 costimulated CD19 CAR T cell infusion elicited no antitumor activity, thus we conclude that antitumor activity mediated by C4-27z CAR T cells is also antigen-specific in vivo.

\section{Enhanced function of the human C4 CAR compared to murine MOv19 CAR in vitro}

Using the same production and concentration protocols in parallel, we found that the C4 CAR-encoding lentivirus has a higher effective titer than the murine MOv19 CAR, possibly the result of more efficient expression of the human scFv on human T cells (Supplementary Figure 2A). Indeed, we observed a multiplicity of infection (MOI) of C4 CAR lentivirus as low as 1 is sufficient to infect $>20 \%$ human T cells, while the MOv19 CAR lentivirus required a MOI of 5 (Supplementary Figure 2B). Thus, for the following experiments, $\mathrm{T}$ cells were infected with a MOI of 2 and 5 of concentrated C4-27z and MOv19-27z vector, respectively, and both $\mathrm{C} 4$ and MOv19 CAR surface expression on T cells were detected via recombinant $\alpha \mathrm{FR}$ protein staining (Figure 4A).

$\mathrm{ScF} v$ s used for CAR construction require a minimal antigen affinity to achieve activation threshold for the engineered T cell, however, higher affinity scFvs do not necessarily induce a more potent activation of CAR T cells than low affinity scFvs [24]. Since the binding affinity of the $\mathrm{C} 4 \mathrm{Fab}$ fragment $\left(2 \times 10^{7} \mathrm{M}^{-1}\right)$ is approximately fivefold weaker than that of the MOv19 antibody [21], we examined whether the potentially lower affinity of the $\mathrm{C} 4$ scFv used to construct the fully human C4 CAR might influence redirected T-cell function via comparison to the MOv19 CAR containing a potentially higher affinity 
A

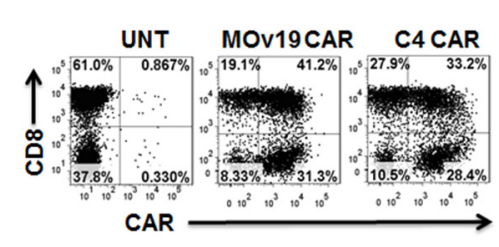

C

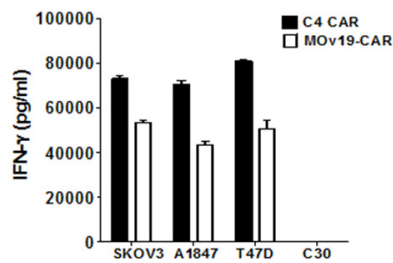

B

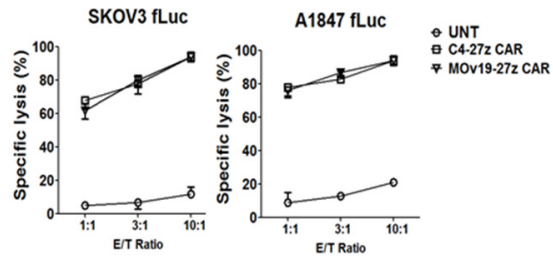

D

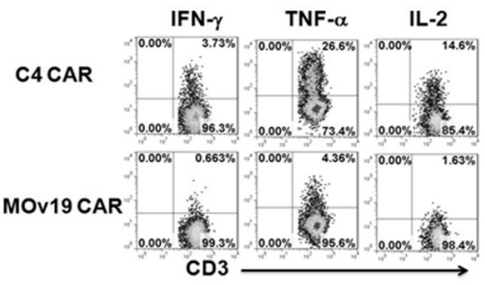

Figure 4: Comparison of anti-tumor activity of $\alpha$ FR-specific $C 4$ and MOv19 CARs with CD27 costimulatory endodomain in vitro. A. C4 and MOv19 CARs expression on primary human T cells can be detected via biotin-labeled recombinant $\alpha \mathrm{FR}$ protein followed by SA-PE. As shown, both CD8+ T and CD8- (CD4+) cells can efficiently express CARs as measured by flow cytometry. B. C4 and MOv19 CARs-transduced T cells showed lytic function in a bioluminescent killing assay. CAR-T cells killed $\alpha \mathrm{FR}+$ SKOV3 and A1847 at the indicated E/T ratio after more than 20 hours. UNT T cells served as negative controls. Mean and SD of triplicate wells from 1 of at least 3 independent experiments is shown. C. C4 or MOv19 CAR T cells were co-cultured with aFR + target cells (SKOV3, A1847 and T47D) and $\alpha$ FR- (C30) at a 1:1 E:T ratio. D. C4 or MOv19 CAR T cells were stimulated with SKOV3 cells for 5-hour in the presence of Golgi inhibitor and analyzed by flow cytometry for intracellular IFN- $\gamma$, TNF- $\alpha$ and IL-2. Results are shown for representative donor $\mathrm{T}$ cells and are reproducible in multiple donors $(n=3)$.

anti- $\alpha$ FR scFv. T cells modified to express either the C4$27 z$ or MOv19-27z CAR specifically lysed $\alpha \mathrm{FR}^{\mathrm{pos}}$ SKOV3 and A1847 tumor cells with approximately equivalent efficiency in overnight co-cultures (Figure 4B). However, in vitro cytokine production analysis showed that MOv1927 z CAR T cells secreted significantly less IFN- $\gamma$ than $\mathrm{C} 4$ CAR T cells at an equivalent 1:1 E:T ratio after overnight co-culture (Figure 4C). This result was validated by 5 -hour intracellular cytokine production assays. Representative fluorescence activated cell sorter (FACS) plots of 5-hour intracellular cytokine expression by tumor-activated CAR T cells show that both $\mathrm{C} 4$ and MOv19 CAR T cells produce IFN- $\gamma$, TNF- $\alpha$ and IL- 2 cytokines when incubated overnight with $\alpha \mathrm{FR}^{\text {pos }} \mathrm{SKOV} 3$ ovarian cancer cells, but MOv19 CAR T cells produced less of these cytokines than C4 CAR T cells (Figure 4D). The frequency of C4 CAR $\mathrm{T}$ cells expressing cytokine was 5.6-fold higher for IFN- $\gamma$, 6.1-fold for higher TNF- $\alpha$ and 9-fold higher for IL-2, than that observed in MOv19 CAR T cells in vitro. UNT $\mathrm{T}$ cells cocultured with $\alpha \mathrm{FR}^{\text {pos }}$ or $\alpha \mathrm{FR}^{\text {neg }}$ cancer cells (not shown), or CAR $\mathrm{T}$ cells cocultured with $\alpha \mathrm{FR}^{\text {neg }}$ cancer cells, did not produce proinflammatory cytokines (Supplementary Figure 3A and 3B).

Our results in vitro suggested that the fully human C4 CAR T cells may be functionally superior to MOv19 CAR T cells. To understand the mechanisms accounting for reduced function by MOv19 CAR T cells, we carefully measured for relative binding to recombinant $\alpha F R$ protein, antigen-induced cell death (AICD) and CAR expression on $\mathrm{T}$ cells after co-incubation with antigen-expressing tumor cells. First, $\mathrm{C} 4$ and MOv19 CAR T cells were pre-loaded with biotin labeled recombinant $\alpha \mathrm{FR}$ protein, and measured for surface protein dissociation over time at either 4 or $37^{\circ} \mathrm{C}$ in the presence of excess non-biotinylated $\alpha \mathrm{FR}$ competitor. Within one hour, less $\alpha \mathrm{FR}$ protein was detectable on the surface of C4 CAR T cells, in comparison to MOv19 $\mathrm{CAR}$, at either temperature and the level of dissociation was dependent on both time and temperature, and was higher in C4 CAR $\mathrm{T}$ cells under all conditions (Figure 5A). Similar results were obtained in titration analysis on the binding of biotinylated $\alpha \mathrm{FR}$ protein to MOv19 and C4 CAR T cells (Supplementary Figure 3C), suggesting that $\mathrm{C} 4$ in the CAR construct had a lower affinity for soluble $\alpha \mathrm{FR}$ antigen than MOv19 CAR. We have shown previously that supraphysiological expression of antigen on the target cell surface can induce antigen induced cell death of CAR T cells [25], however, the frequency of apoptotic cells in C4 CAR or MOv19-CAR T cells after stimulation with SKOV3 cells was similar, as measured by Annexin V+/7-AAD+ staining (Supplementary Figure 4A and 4B), suggesting that AICD did not play a major role. Lastly, stimulation with SKOV3 cancer cells, which express a high level of $\alpha \mathrm{FR}$, induced a rapid and marked down-modulation of surface MOv19 CAR expression following antigen engagement (Figure 5B). Five hours after exposure to tumor cells, MOv19 CAR frequency was rapidly decreased from about $65 \%$ of $\mathrm{T}$ cells to $\sim 1 \%$. This finding was additionally confirmed by using $\alpha \mathrm{FR}^{\mathrm{pos}}$ 
A
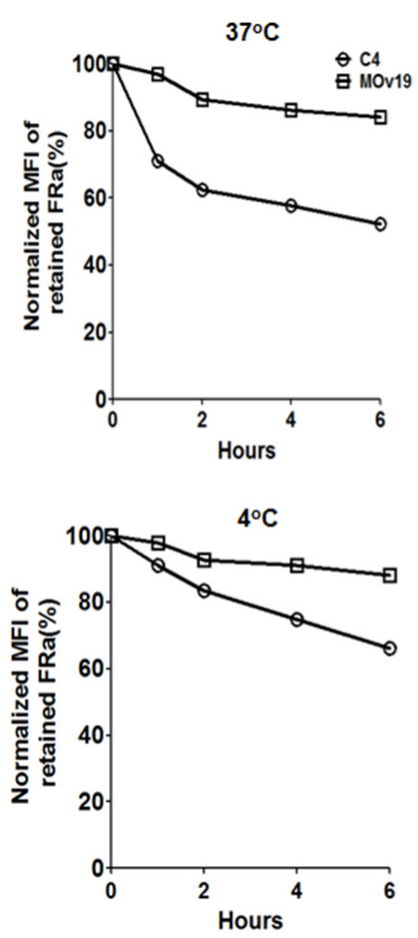

B

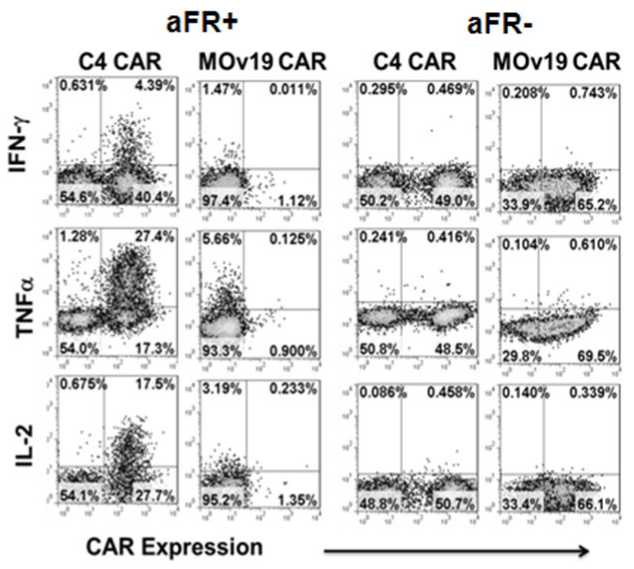

C

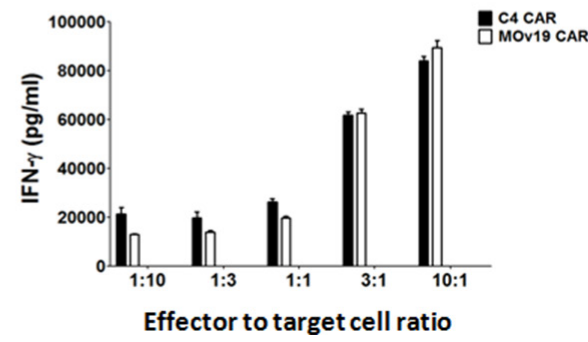

Figure 5: CAR down-modulation may impair the antitumor activity of MOv19 CAR but not C4 CAR. A. $\alpha$ FR dissociation assay. C4-27z or MOv19-27z CAR T cells were labeled with recombinant biotinylated $\alpha \mathrm{FR}$ protein and then incubated at $37^{\circ} \mathrm{C}(\mathrm{Upper})$ or $4^{\circ} \mathrm{C}$ (Lower) in a time course assay in the presence of a ten-fold excess of nonbiotinylated $\alpha \mathrm{FR}$. Antigen retention on the cell surface was assessed by flow cytometry by adding SA-PE after the end of each culture period. Percent retained $\alpha \mathrm{FR}$ (y-axis) was normalized and scored as mean fluorescence intensity (MFI) postincubation $\div$ preincubation MFI $\times 100$. B. C4 and MOv19 CAR T cells were stimulated with SKOV3 or C30 cells for 5-hour in the presence of Golgi inhibitor and analyzed by flow cytometry for T cell surface of CAR expression and intracellular IFN- $\gamma$, TNF- $\alpha$ and IL-2. C. IFN- $\gamma$ release assay of C4 and MOv19 CAR T cells after overnight co-culture with $\alpha$ FR + tumor cells at 1:10, 1:3, 1:1, 3:1 and 10:1 E:T ratios. Results are shown for representative donor $\mathrm{T}$ cells and are reproducible across multiple donors $(n=3)$.

A1847 cells and the breast cancer cell line T47D, which also express high levels of $\alpha$ FR (Supplementary Figure 4C). By comparison, the C4 CAR was not markedly down-modulated (Figure 5B) and intracellular cytokine expression analysis showed that $\mathrm{T}$ cells with maintained C4 CAR surface expression produced IFN- $\gamma$, TNF- $\alpha$ and IL-2, while cytokine production was exclusively detected in the CAR-negative fraction of the MOv19 group, indicating that CAR down-modulation and cytokine production had occurred following antigen encounter.

Given differences in relative affinity, we hypothesized that overall avidity between CAR and target molecule might account for the observed difference in CAR expression. We therefore evaluated the impact of $\mathrm{T}$ cell to target cell ratio on relative CAR expression by $\mathrm{C} 4$ or MOv19 CAR T cells following co-culture with SKOV3 cells. At lower E:T ratios of 1:10, 1:3 and 1:1, MOv19 CAR $T$ cells showed a marked, dose-dependent downmodulation in CAR expression compared with C4 CAR, which maintained $\sim 50 \%$ of initial CAR expression at the lowest E:T ratio tested (Supplementary Figure 5). However, at high E:T ratios of 3:1 and 10:1 where tumor antigen is more limiting, $\mathrm{T}$ cells bearing either $\mathrm{C} 4$ or MOv19 CAR maintained high CAR expression. Consistent with changes in CAR expression after antigen stimulation, C4 CAR T cells released more IFN- $\gamma$ than MOv19 CAR T cells at E:T ratios of 1:10, 1:3 and 1:1, but similar amounts at E:T ratios of 3:1 and 10:1 (Figure 5C). Thus, CAR down-modulation occurs in an antigen dose-dependent fashion with anti- $\alpha \mathrm{FR}$ CAR T cells bearing the higher affinity MOv19 $\mathrm{scFv}$ being more sensitive to low antigen level.

\section{Comparable antitumor activity of $\mathrm{C} 4$ and MOv19 CAR T cells in vivo}

To compare the antitumor capacity of C4 CAR T cells with MOv19 CAR T cells in vivo, NSG mice with large, established subcutaneous SKOV3 tumors $(\sim 300$ $\mathrm{mm}^{3}$ ) received intravenous injections of $10^{7} \mathrm{CAR}+\mathrm{T}$ cells on days 40 and 47 post-tumor inoculation. Tumors in animals treated with saline, UNT or CD19-27z CAR $\mathrm{T}$ cells continued to grow rapidly. In contrast, mice receiving C4-27z or MOv19-27z CAR T cells experienced 

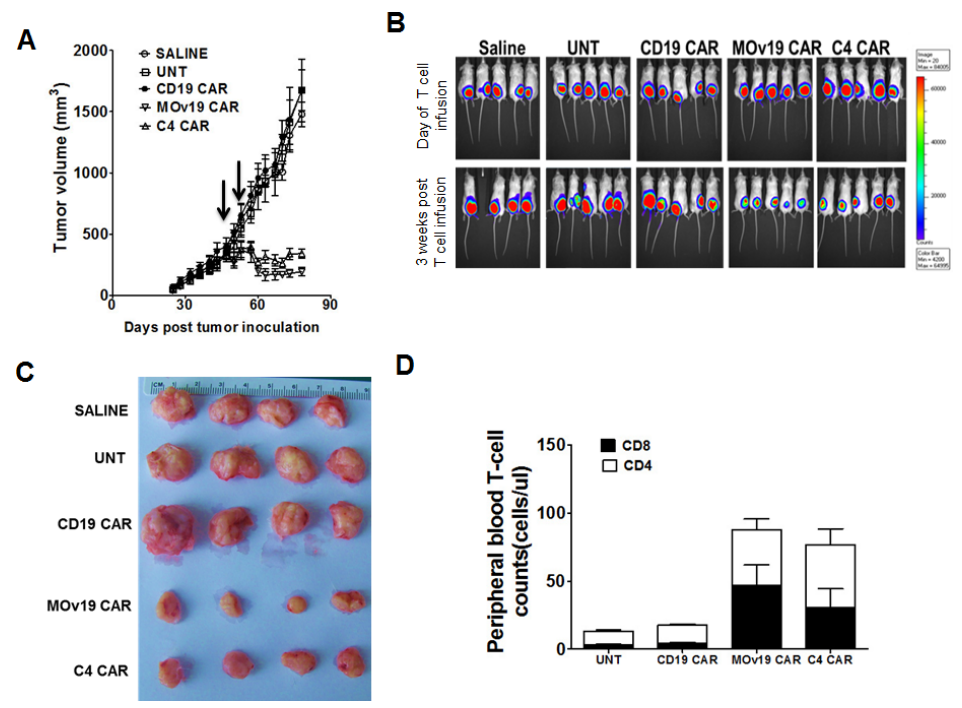

D

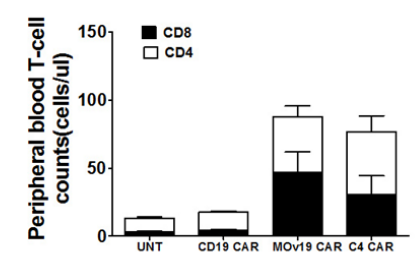

Figure 6: Antitumor activity of C4-CAR T cells is comparable to MOv19 CAR T cells. A. Tumor regression mediated by C4-27z and MOv19-27z CAR T cells. NSG mice bearing established subcutaneous tumor were treated with i.v. injections of $1 \times 10^{7} \mathrm{C} 4-27 \mathrm{z}$ and MOv19-27z CAR+ T cells or control CD19-27z and UNT T cells or saline on day 40 and 45 . Tumor growth was assessed by caliper measurement. Tumors treated with $\mathrm{C} 4-27 \mathrm{z}$ CAR or MOv19 CAR T cells ( $60 \%$ CAR expression) regressed (arrows indicate days of $\mathrm{T}$ cell infusion); tumors treated with saline, UNT or CD19-27z CAR T cells did not regress 3 weeks post-first T cell dose. B. SKOV3 fLuc+ bioluminescence signal was decreased in C4-27z and MOv19-27z CAR T cells treated mice compared with the CD19-27z and the control treatment groups 3 weeks after the first $\mathrm{T}$ cell dose. C. Macroscopic evaluation of resected tumor specimens following $\mathrm{T}$ cell therapy. Tumors were harvested from mice at the time of euthanasia, nearly 45 days after first T cell injection. D. Stable persistence of C4 CAR and MOv19 CAR T cells in vivo. Peripheral blood was collected 3 weeks after the first $T$ cell infusion and quantified for the absolute number of human $\mathrm{CD} 4+$ and $\mathrm{CD} 8+\mathrm{T}$ cells $/ \mu \mathrm{l}$ of blood. Mean cell count $\pm \mathrm{SEM}$ is shown with $n=5$ for all groups.

tumor regression $(p<0.0001)$, compared with all 3 control groups at the latest evaluated time point. The antitumor activity of MOv19-27z CAR T cells appeared slightly better than that of C4-27z CAR T cells, but were statistically similar even at the final time point $(p=0.058$; Figure 6A). BLI of tumor xenografts before and 3 weeks after $\mathrm{T}$ cells injection showed progressive growth of tumors in all animals receiving control $\mathrm{T}$ cells but not in CAR T cells groups (Figure 6B). Tumor BLI results were consistent with the size of resected residual tumors (Figure 6C). Next, we analyzed the persistence of transferred T-cells in the peripheral blood 3 weeks following adoptive transfer and detected higher numbers of CD4+ and CD8+ $\mathrm{T}$ cells in mice treated with both the $\mathrm{C} 4$ and MOv19 CAR T cells groups compared with the UNT and CD19-27z CAR T cells treatment group (Figure 6D), suggesting that tumor antigen recognition drives the survival of the adoptively transferred $\mathrm{T}$ cells in vivo. These results demonstrated that the anti-tumor activity of the C4 CAR is comparable to the MOv19 CAR, which was described previously $[19,20]$, and confirm that the C4 CAR, despite its decreased affinity, is suitable for in vivo application.

\section{Anti-aFR CAR with lower affinity may decrease the risk of "on-target" toxicity}

On-target toxicities have been observed in clinical trials [26-28] with CAR T-cells specific for tumor associated antigens that are expressed at low levels on normal cells, and a critical issue to be addressed is whether CARs with higher affinity may increase the risk of toxicity. In a report by Chmielewski et al., higher affinity CARs specific for HER-2 antigen exhibited less discrimination between target cells with high or low Ag expression levels [24]. To investigate the functional effect of exposure of primary human $\mathrm{T}$ cells modified with C4 CAR or MOv19 CAR to normal cells expressing low levels of $\alpha \mathrm{FR}$, we analyzed cytokine production of C4 CAR and MOv19 CAR T-cells after co-culture with human embryonic kidney $293 \mathrm{~T}$ cells or normal epithelial ovarian cell line IOSE 6, which express low but detectable levels of $\alpha \mathrm{FR}$, and $\alpha \mathrm{FR}^{\text {pos }} \mathrm{SKOV} 3$ cells (Figure 7A). C4 and MOv19 CAR T cells responded against SKOV3 with greater activity observed again from C4 CAR T cells. However, greater IFN- $\gamma$ cytokine production was observed from the MOv19 CAR T cells in response to low antigen expressing cells, suggesting that MOv19 CAR T cells are more functionally avid and sensitive to low antigen (Figure 7B). Similar to what we observed in overnight IFN- $\gamma$ release assays, 5-hour intracellular cytokine secretion assays showed that more MOv19 CAR T cells produced IFN- $\gamma$ and TNF- $\alpha$ in response to low antigen on normal cells (Figure 7C), which is one primary proposed contributor to the "ontarget" cytokine storm [26], as compared with C4 CAR $\mathrm{T}$ cells. These data suggest that the newly described 


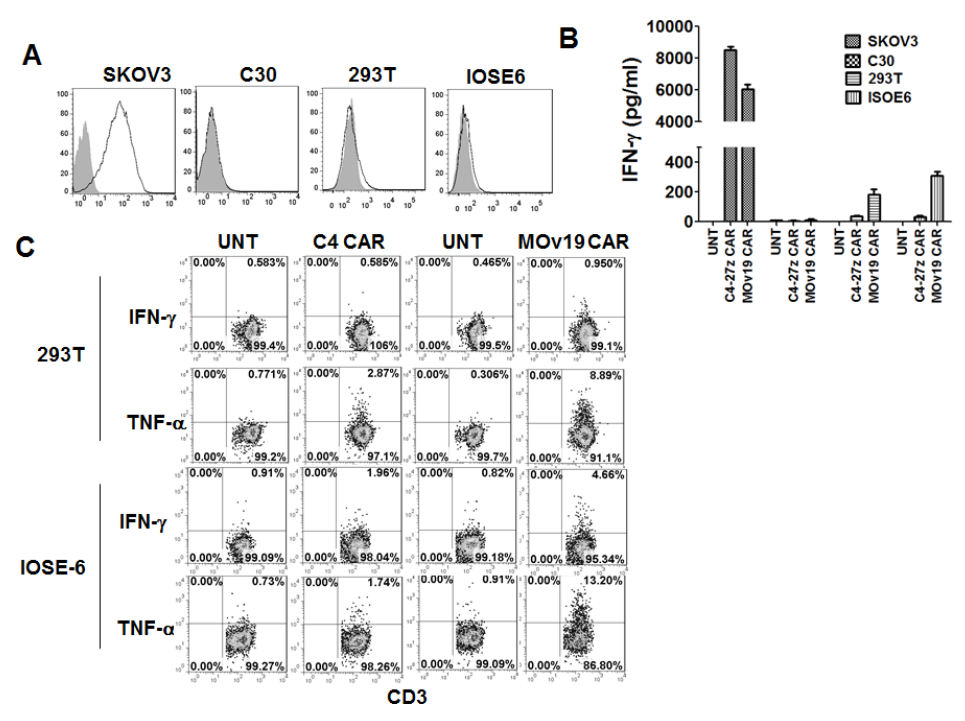

Figure 7: C4 CAR T cells showed minimal cytokine release in vitro. A. Human embryonic kidney 293T cells and normal epithelial ovarian cell line IOSE6 express very low level of $\alpha$ FR. SKOV3 and C30 served as positive and negative controls, respectively. B. $\mathrm{C} 4-27 \mathrm{z}$ CAR T cells secret minimal amount of IFN- $\gamma$ following overnight incubation with normal $293 \mathrm{~T}$ cells and IOSE 6 cell lines expressing low levels of surface $\alpha$ FR compared to MOv19-27z CAR T cells. C. C4 and MOv19 CAR T cells were stimulated with 293T or IOSE6 cells for 5 -hour in the presence of Golgi inhibitor and analyzed by flow cytometry for intracellular IFN- $\gamma$ and TNF- $\alpha$.

C4 CAR may have a more appropriate affinity for the delivery of safe and effective engineered $\mathrm{T}$ cell therapy of cancer.

\section{DISCUSSION}

$\alpha \mathrm{FR}$ is an attractive target for cancer immunotherapy due to its overexpression on the surface of epithelial ovarian cancer and many other epithelial cancers. $\alpha \mathrm{FR}$ is expressed at low levels in some normal tissues, however its expression is largely restricted to the apical surface of some polarized epithelial cells of normal tissues [16], where it is inaccessible to circulating drugs. This suggests that a "druggable window" may exist for the creation of safe, effective therapy. We have recently constructed a murine MOv19 scFv-based $\alpha$ FR-specific CAR that overcomes the limitations of past CAR approaches by improving the persistence and anti-tumor activity of transferred CAR T cells in vivo $[19,20]$. Here, we constructed a novel fully human anti-FR C4 CAR and addressed the potential issue of CAR transgene immunogenicity and risk for toxicity. We observed that $\mathrm{C} 4 \mathrm{CAR}$-modified $\mathrm{T}$ cells have in vitro activity against ovarian cancer and breast cancer cells and in vivo activity against $\alpha \mathrm{FR}$ expressing ovarian cancer.

T-cell based targeting of $\alpha \mathrm{FR}$ has been tested in patients with advanced ovarian cancer with encouraging results. Kershaw and colleagues [17] transferred T cells that were retargeted to $\alpha \mathrm{FR}$ by a first-generation MOv18 scFv-based CAR to immunocompetent patients with advanced ovarian cancer. Therapy using MOv18-z CAR was safe and feasible; however, no patient experienced a tumor response which was attributed to a lack of transferred T-cells persistence after infusion, poor tumor localization, and the development of a human anti-mouse antibody (HAMA) that reduced CAR T-cell activity in in vivo study. Unlike previous MOv18 and MOv19 CARs that utilize scFvs derived from mouse monoclonal antibodies, the fully human anti- $\alpha \mathrm{FR}$ C4 CAR is predicted to be less likely to induce xenogeneic HAMA or T cell responses in humans, which have limited their impact in vivo.

The therapeutic success of adoptive therapy with CAR T cells depends on the appropriate costimulation of $\mathrm{CD} 3 z$ to induce full T-cell activation. These costimulatory cytoplasmic signaling domains derived from the T-cell costimulatory molecules CD28 [29-31], 4-1BB (CD137) [20, 30], OX40 (CD134) [30], ICOS [32] or CD27 [19]. $\mathrm{CD} 27$ is a member of the TNF receptor family, which is also known as a $\mathrm{T}$ cell costimulatory molecule. This work builds upon our previous study which showed CD27 costimulation promotes CAR-T cell survival and antitumor function in vivo [19]. More recently, Duong et al. [33] demonstrated that HER2 specific CAR T cells bearing the DAP10, CD27 and CD3z inhibited tumor growth to a greater degree than $\mathrm{T}$ cells expressing the $\mathrm{CD} 28 \mathrm{z}$ CAR, suggesting an important role of CD27 costimulation. Consistent with previous study [19], CD27-bearing C4 CAR-T cells facilitated superior regression of established tumors in a xenograft model of subcutaneous human ovarian compared with the marginal inhibition achieved with conventional, non-costimulated CAR-T cells. In addition, CD27-bearing C4 CAR-T cells significantly controlled the tumor growth in metastatic intraperitoneal human ovarian cancer model. Notably, T cells modified to 
express an irrelevant anti-CD19 CAR were unable to alter tumor growth demonstrating the high specificity of the CAR system and ruling out the possibility of xenogeneity as the source of the tumor response.

The C4 CAR expressed on the $\mathrm{T}$ cell surface exhibited reduced association and increased dissociation of $\alpha$ FR protein, relative to MOv19 CAR T cells. The decreased affinity of the fully human C4 CAR could affect $\mathrm{T}$-cell recognition. However, a direct comparison of cytokine production after tumor engagement by $\mathrm{T}$ cells modified with the $\mathrm{C} 4$ and MOv19 CARs showed that the C4 CAR with lower affinity was superior in conditions of high antigen exposure. This may be due to the rapid internalization of the higher affinity MOv19 CAR upon encountering high levels of antigen. With lower antigen availability, the anti-tumor activity of C4 CAR T cells is more comparable to MOv19 CAR T cells. It would be interesting to determine the optimal ratio of CAR $T$ cells and tumor cells necessary to enhance CAR T cell function in vitro and in vivo; this would likely require quantitative analysis using mathematical model described previously [34]. In comparing relative antitumor activity in vivo, we found that $\mathrm{T}$ cells expressing the high-affinity MOv19 CAR mediated slightly superior activity in vivo compared with the C4 CAR. However, this difference is not statistically significant, suggesting that the affinity of C4 CAR is adequate for in vivo application.

Possible on-target, off-tumor toxicities resulting from the expression of TAAs on normal tissues need to be considered in the application of CAR approach. The development of high affinity CAR or TCR with great antitumor activity can lead to severe toxicity [26], [35]. C4 CAR T cells release less cytokine compared with MOv19 CAR T cells when encountering normal cells expressing low levels of $\alpha \mathrm{FR}$, yet retained enhanced reactivity against cancer cells. Thus, the relative lower affinity of C4 CAR could theoretically decrease the risk of on-target toxicity, while the higher affinity MOv19 CAR may increase this risk in vivo. However, the potential for off-target toxicity in the clinical setting is not precluded by these studies. To this end, one may utilize an RNA electroporation approach that results in transient CAR expression on electroporated $\mathrm{T}$ cells to provide a safer platform in the clinical setting. Moreover, it should be possible to tune scFv affinity by mutagenesis in vitro if it was safe in early clinical trials.

In consideration of clinical application, there are several advantages to the use of fully human $\mathrm{C} 4$ CAR T cells over murine MOv18 or MOv19 CAR T cells as a therapy for $\alpha \mathrm{FR}$ expressing cancer. The first advantage is that it is likely to be less immunogenic than murine $\mathrm{scFv}$ format upon application for adoptive $\mathrm{T}$ cell immunotherapy in patients. The immunogenicity of mouse transgenes is noted in numerous trials of adoptive immunotherapy using autologous $\mathrm{T}$ cells modified to express mouse-derived scFvs or tumor antigen-specific TCRs [17, 36, 37], which limited the persistence and function of the transferred gene-modified cells. The second advantage is that $\mathrm{C} 4 \mathrm{CAR}$ can be more easily expressed on human $\mathrm{T}$ cell surface compared with MOv19 CAR when using the same MOI for each vector. These results suggest a possible significant cost savings for clinical grade lentivirus production. The third advantage is that the human C4 CAR with decreased affinity may release lower levels of proinflammatory cytokines upon encounter with healthy cells that express low levels of $\alpha \mathrm{FR}$ while still retaining comparable antitumor activity to MOv19 CAR $\mathrm{T}$ cells in vivo. In conclusion, our study shows that fully human C4-27z CAR T cells destroy $\alpha$ FR-positive ovarian cancer and breast cancer cells in vitro and mediate ovarian cancer regression in vivo. These data provide the rationale for the clinical investigation of C4 CAR T-cell therapy of a wide spectrum of $\alpha \mathrm{FR}$ expressing epithelial malignancies.

\section{MATERIALS AND METHODS}

\section{Cell lines}

Lentivirus packaging was performed in the immortalized normal fetal renal 293T cell line purchased from ATCC. Human cell lines used in immune based assays include the established human ovarian cancer cell lines SKOV3, A1847, T47D and C30. The human lymphoid cell lines SUP-T1 was used for lentivirus titer analysis. For bioluminescence assays, target cancer cell lines were transfected to express firefly luciferase (fLuc). The mouse malignant mesothelioma cell line, AE17 (kindly provided by Steven Albelda, University of Pennsylvania) was used as negative control. All cell lines were maintained in R10 medium: RPMI-1640 supplemented with 10\% heat inactivated FBS, $100 \mathrm{U} / \mathrm{mL}$ penicillin, $100 \mathrm{mg} / \mathrm{mL}$ streptomycin sulfate, $10 \mathrm{mmol} / \mathrm{L} \mathrm{HEPES).}$

\section{CAR construction and lentivirus production}

The pHEN2 plasmid containing the anti- $\alpha$ FR C4 scFv kindly provided by Dr. Silvana Canevari was used as a template for PCR amplification of a 729-bp C4 fragment using the following primers: 5'-ataggatcccagctggtggagtctgggggaggc-3' (BamHI is underlined) and 5'-atagctagcacctaggacggtcagcttggtccc- $3^{\prime}$ (NheI is underlined). Third generation self-inactivating lentiviral expression vectors pELNS previously described were digested with BamHI and NheI and gel purified. The digested PCR products were then inserted into the pELNS vector containing CD3z or CD27-CD3z $\mathrm{T}$ cell signaling domains in which transgene expression is driven by the elongation factor- $1 \alpha(\mathrm{EF}-1 \alpha)$ promoter. The resulting construct was designated pELNS-C4-z or $\mathrm{C} 4-27 \mathrm{z}$. High-titer replication-defective lentiviral vectors were produced and concentrated as previously described [31]. Briefly, 293T cells were seeded in $150 \mathrm{~cm}^{2}$ flask and transfected using Express In (Open 
Biosystems) according to manufacturer's instructions. Fifteen micrograms of $\alpha \mathrm{FR}$-specific CAR transgene plasmid were cotransfected with 7 ug pVSV-G (VSV glycoprotein expression plasmid), 18 ug pRSV.REV (Rev expression plasmid) and $18 \mathrm{ug}$ pMDLg/p.RRE (Gag/Pol expression plasmid) with $174 \mathrm{ul}$ Express In (1 ug/ul) per flask. Supernatants were collected at $24 \mathrm{~h}$ and $48 \mathrm{~h}$ after transfection, concentrated 10 -fold by ultracentrifugation for 2 hours at 28, $000 \mathrm{rpm}$ with a Beckman SW32Ti rotor (Beckman Coulter). The viruses were aliquoted into tubes and stored at $-80^{\circ} \mathrm{C}$ until ready to use for titering or experiments. All lentiviruses used in the experiments were from concentrated stocks.

\section{Determination of lentiviral titer}

Titers of concentrated lentiviral vectors encoding $\alpha$ FR CAR were determined by serially (3-fold) diluting vector preparations in R10 medium and transduce SUP-T1 cells. Briefly, SUP-T1 cells (20,000 cells/100 ul/ well) were seeded in a single well of a 96 -well plate and 50 ul 3-fold diluted vector supernatant was transferred and incubated overnight. The next day, feed the cells with 100 ul pre-warmed R10 medium. Two days post transduction, vector titers were determined by flow cytometry applying standard flow cytometric methods for analysis of CAR expression. The titers (transducing units [TU] $(\%$ positive/100 $) \times 2 \mathrm{E} 4 \times 20 \times$ dilution. All the experiments were repeated at least three times and average titers obtained from the experiments were used for data analysis.

\section{Human $T$ cells and transfection}

Primary human CD4+ and CD8+ $\mathrm{T}$ cells, purchased from the Human Immunology Core at University of Pennsylvania, were isolated from healthy volunteer donors following leukapheresis by negative selection. All specimens were collected under a protocol approved by a University Institutional Review Board, and written informed consent was obtained from each donor. T cells were cultured in R10 medium and stimulated with anti-CD3 and anti-CD28 monoclonal antibodies (mAb)-coated beads (Invitrogen). Eighteen to 24 hours after activation, human $\mathrm{T}$ cells were transduced using a spinoculation procedure. Briefly, $0.5 \times 10^{6} \mathrm{~T}$ cells were infected with a multiplicity of infection (MOI) of 2 and 5 of concentrated $\mathrm{C} 4-27 \mathrm{z}$ and MOv19-27z vector, respectively. Mixtures of cells and vectors were centrifuged at room temperature for $90 \mathrm{~min}(2,500 \mathrm{rpm})$ in a table-top centrifuge (Sorvall ST 40). Human recombinant interleukin-2 (IL-2; Novartis) was added every 2-3 days to a $100 \mathrm{IU} / \mathrm{mL}$ final concentration and a cell density of $0.5 \times 10^{6}$ to $1 \times 10^{6}$ cells $/ \mathrm{mL}$ was maintained. Once engineered T-cell cultures appeared to rest down, as determined by both decreased growth kinetics and cell-sizing determined using the Multisizer 3 Coulter Counter (Beckman Coulter), the T cells were used for functional analysis.

\section{Flow cytometric analysis}

The following monoclonal antibodies were used for phenotypic analysis: APC-Cy7 anti-human CD3; FITC antihuman CD4; APC anti-human CD8; PE-anti-human CD45; PE anti-human CD137. 7-Aminoactinomycin D (7-AAD) was used for viability staining. All monoclonal antibodies were purchased from BD Biosciences. In T cell transfer experiments, peripheral blood was obtained via retro-orbital bleeding and stained for the presence of human CD45, CD4, and CD8 T cells. After gating on the human $\mathrm{CD} 45+$ population, the CD4+ and CD8+ subsets were quantified using TruCount tubes (BD Biosciences) with known numbers of fluorescent beads as described in the manufacturer's instructions. Tumor cell surface expression of $\alpha \mathrm{FR}$ was performed using MOv18 mAb followed by APC-labeled goat anti mouse Ab. T cell surface expression of the both $\mathrm{C} 4$ and MOv19 CAR was evaluated using biotin-labeled recombinant $\alpha \mathrm{FR}$ protein (R\&D Systems, Inc) followed by StreptavidinAPC (eBioscience, Inc.) or biotin-labeled rabbit antihuman IgG and goat anti-Mouse $\operatorname{IgG~F}\left(\mathrm{ab}\right.$ ') ${ }_{2}$ fragment followed by Streptavidin-APC, respectively. To determine cytokine production in CAR T cells, cells were cocultured with $\mathrm{FR}^{\text {pos }}$ ovarian cancer cells for $5 \mathrm{~h}$. After surface markers were stained, cells were fixed and permeabilized using Cytofix/Cytoperm and Perm/Wash buffer (BD Biosciences) according to the manufacturer's instructions. Then cells were stained with fluorescence-conjugated cytokine antibodies including PE anti-human IFN- $\gamma$, Pacific blue anti-human TNF- $\alpha$ or FITC anti-human IL-2 before analysis. Flow cytometry was performed with a BD FACS Canto II flow cytometer (BD Biosciences) and flow cytometric data were analyzed with FlowJo version 7.2.5 software (Tree Star, Ashland, OR).

\section{Cytokine release assays}

Cytokine release assays were performed by coculture of $1 \times 10^{5} \mathrm{~T}$ cells with $1 \times 10^{5}$ target cells per well in triplicate in 96-well flat bottom plates in a 200 ul volume of R10 medium. After 20-24 hours, coculture supernatants were assayed for presence of IFN- $\gamma$ and IL-2 using an ELISA Kit, according to manufacturer's instructions (Biolegend, San diego, CA). Values represent the mean of triplicate wells.

\section{Cytotoxicity assays}

For the cell-based bioluminescence assays, $5 \times 10^{4}$ firefly Luciferase (fLuc)-expressing tumor cells were cultured with R10 media in the presence of different ratios of transduced $\mathrm{T}$ cells with the use of a 96-well 
Microplate (BD Biosciences). After incubation for $\sim 20$ hours at $37^{\circ} \mathrm{C}$, each well was filled with $50 \mathrm{uL}$ of DPBS resuspended with $1 \mathrm{ul}$ of D-luciferin $(0.015 \mathrm{~g} / \mathrm{mL})$ and imaged with the Xenogen IVIS Spectrum. Percent tumor cell viability was calculated as the mean luminescence of the experimental sample minus background divided by the mean luminescence of the input number of target cells used in the assay minus background times 100. All data are represented as a mean of triplicate wells.

\section{Antigen dissociation assay}

C4-27z or MOv19-27z CAR (both 90\% CAR expression) $\mathrm{T}$ cell were harvested, washed once with fluorescent-activated cell sorting buffer and stained with $0.5 \mu \mathrm{g} / \mathrm{ml}$ biotinylated- $\alpha \mathrm{FR}$ protein for 30 minutes at $4^{\circ} \mathrm{C}$. Then the cells were washed two times before the addition of $5 \mu \mathrm{g} / \mathrm{ml}$ of nonbiotinylated $\alpha \mathrm{FR}$ competitor and incubation at a $4^{\circ} \mathrm{C}$ or $37^{\circ} \mathrm{C}$ for different time points $(0<t<6$ hours $)$. At indicated time points cells were removed from $4^{\circ} \mathrm{C}$ or $37^{\circ} \mathrm{C}$, washed again, labeled with biotinylated streptavidin, washed and analyzed for percent $\alpha \mathrm{FR}$-positive and mean fluorescence intensity by flow cytometry.

\section{Titration analysis on the binding of $\alpha \mathrm{FR}$ protein to $\alpha$ FR CAR T cells}

Activated $\mathrm{T}$ cells were transduced with lentiviral vector expressing MOv19-27z or C4-27z-CAR and analyzed for CAR expression on day 14 . One hundred thousand UNT or CAR T cells were stained with $0.2,0.5$, $1,2,5,10,20,50$ or $120 \mathrm{nM} /$ sample of biotinylated $\alpha \mathrm{FR}$. $\mathrm{T}$ cells were then washed and stained with phycoerythrin (PE)-conjugated streptavidin (SA). No $\alpha$ FR protein T cells sample was stained with SA-PE alone.

\section{Xenograft model of ovarian cancer}

All animals were obtained from the Stem Cell and Xenograft Core of the Abramson Cancer Center, University of Pennsylvania. Six to 12-week-old NOD/ $\mathrm{SCID} / \gamma$-chain-/- (NSG) mice were bred, treated and maintained under pathogen-free conditions in-house under University of Pennsylvania IACUC approved protocols. For an established ovarian cancer model, 6 to 12-weekold female NSG mice were inoculated s.c. with $3 \times 10^{6}$ SKOV 3 fLuc + cells on the flank on day 0 . After tumors become palpable at about 1 month, human primary $\mathrm{T}$ cell (CD4+ and $\mathrm{CD} 8+\mathrm{T}$ cells used were mixed at 1:1 ratio) were activated, and transduced as described above. After 2 weeks of $\mathrm{T}$ cell expansion, when the tumor burden was $\sim 200-300 \mathrm{~mm}^{3}$, mice were treated with T cells. The route, dose, and timing of T-cell injections is indicated in the individual figure legends. Tumor dimensions were measured with calipers, and tumor volumes calculated using the formula $V=1 / 2\left(\right.$ length $\times$ width $\left.^{2}\right)$, where length is greatest longitudinal diameter and width is greatest transverse diameter. Animals were imaged prior to $\mathrm{T}$ cell transfer and about every week thereafter to evaluate tumor growth. Photon emission from fLuc + cells was quantified using the "Living Image" software (Xenogen) for all in vivo experiments. Tumors were resected immediately after euthanasia approximately 40 days after first $\mathrm{T}$ cell dose for size measurement and immunohistochemistry.

For the intraperitoneal model of ovarian cancer, NSG mice were injected i.p. with $5 \times 10^{6} \mathrm{SKOV} 3 \mathrm{fLuc}+$ cells. Twenty days after peritoneal inoculation, mice bearing well-established SKOV3 tumors were divided into groups and treated. Mice were sacrificed and necropsied when the mice became distressed and moribund. To monitor the extent of tumor progression, the mice were imaged weekly or biweekly and body weights of the mice were measured. In all models, 4-5 mice were randomized per group prior to treatment.

\section{Bioluminescence imaging}

Tumor growth was also monitored by Bioluminescent imaging (BLI). BLI was done using Xenogen IVIS imaging system and the photons emitted from fLuc-expressing cells within the animal body were quantified using Living Image software (Xenogen). Briefly, mice bearing SKOV3 fLuc+ tumor cells were injected intraperitoneally with D-luciferin $(150 \mathrm{mg} / \mathrm{kg}$ stock, $100 \mu \mathrm{L}$ of D-luciferin per 10 grams of mouse body weight) suspended in PBS and imaged under isoflurane anesthesia after 5 10 minutes. A pseudocolor image representing light intensity (blue, least intense; red, most intense) was generated using Living Image. BLI findings were confirmed at necropsy.

\section{Statistical analysis}

The data are reported as means and SD. Statistical analysis was performed by the use of 2-way repeatedmeasures ANOVA for the tumor burden (tumor volume, photon counts). Student $t$ test was used to evaluate differences in absolute numbers of transferred $\mathrm{T}$ cells, cytokine secretion, and specific cytolysis. GraphPad Prism 5.0 (GraphPad Software) was used for the statistical calculations. $P<0.05$ was considered significant.

\section{ACKNOWLEDGMENTS}

The authors gratefully acknowledge Drs. Silvana Canevari, Carl H. June, Gwenn Danet-Desnoyers and Michael C. Milone for helpful suggestions, discussions, protocols and reagents. This work was supported by grants from the Ovarian Cancer Research Foundation and the Basser Research Center for BRCA, as well as generous support from the Kronish Ovarian Cancer Research Fund and the Bethesda Foundation. 


\section{CONFLICTS OF INTEREST}

None.

\section{REFERENCES}

1. Barrett DM, Singh N, Porter DL, Grupp SA, June CH. Chimeric Antigen Receptor Therapy for Cancer. Annu Rev Med. 2014; 65:333-347.

2. Gross G, Waks T, Eshhar Z. Expression of immunoglobulin-T-cell receptor chimeric molecules as functional receptors with antibody-type specificity. Proc Natl Acad Sci U S A. 1989; 86:10024-10028.

3. Eshhar Z. The T-body approach: redirecting $\mathrm{T}$ cells with antibody specificity. Handb Exp Pharmacol. 2008; 329-342.

4. Grupp SA, Kalos M, Barrett D, Aplenc R, Porter DL, Rheingold SR, Teachey DT, Chew A, Hauck B, Wright JF, Milone MC, Levine BL, June $\mathrm{CH}$. Chimeric antigen receptor-modified T cells for acute lymphoid leukemia. N Engl J Med. 2013; 368:1509-1518.

5. Kochenderfer JN, Wilson WH, Janik JE, Dudley ME, Stetler-Stevenson M, Feldman SA, Maric I, Raffeld M, Nathan DA, Lanier BJ, Morgan RA, Rosenberg SA. Eradication of B-lineage cells and regression of lymphoma in a patient treated with autologous $\mathrm{T}$ cells genetically engineered to recognize CD19. Blood. 2010; 116:4099-4102.

6. Kochenderfer JN, Yu Z, Frasheri D, Restifo NP, Rosenberg SA. Adoptive transfer of syngeneic T cells transduced with a chimeric antigen receptor that recognizes murine CD19 can eradicate lymphoma and normal B cells. Blood. 2010; 116:3875-3886.

7. Porter DL, Levine BL, Kalos M, Bagg A, June CH. Chimeric antigen receptor-modified T cells in chronic lymphoid leukemia. N Engl J Med. 2011; 365:725-733.

8. Brentjens RJ, Davila ML, Riviere I, Park J, Wang X, Cowell LG, Bartido S, Stefanski J, Taylor C, Olszewska M, Borquez-Ojeda O, Qu J, Wasielewska T, He Q, Bernal $\mathrm{Y}$, Rijo IV, et al. CD19-targeted T cells rapidly induce molecular remissions in adults with chemotherapy-refractory acute lymphoblastic leukemia. Sci Transl Med. 2013; 5: $177 \mathrm{ra138.}$

9. Kalli KR, Oberg AL, Keeney GL, Christianson TJ, Low PS, Knutson KL, Hartmann LC. Folate receptor alpha as a tumor target in epithelial ovarian cancer. Gynecol Oncol. 2008; 108:619.

10. Parker N, Turk MJ, Westrick E, Lewis JD, Low PS, Leamon CP. Folate receptor expression in carcinomas and normal tissues determined by a quantitative radioligand binding assay. Anal Biochem. 2005; 338:284-293.

11. Knutson KL, Krco CJ, Erskine CL, Goodman K, Kelemen LE, Wettstein PJ, Low PS, Hartmann LC, Kalli KR. T-cell immunity to the folate receptor alpha is prevalent in women with breast or ovarian cancer. Journal of Clinical Oncology. 2006; 24:4254-4261.

12. O'Shannessy DJ, Yu G, Smale R, Fu Y-S, Singhal S, Thiel RP, Somers EB, Vachani A. Folate receptor alpha expression in lung cancer: diagnostic and prognostic significance. Oncotarget. 2012; 3:414.

13. Shia J, Klimstra DS, Nitzkorski JR, Low PS, Gonen M, Landmann R, Weiser MR, Franklin WA, Prendergast FG, Murphy L. Immunohistochemical expression of folate receptor $\alpha$ in colorectal carcinoma: patterns and biological significance. Human pathology. 2008; 39:498-505.

14. Bueno R, Appasani K, Mercer H, Lester S, Sugarbaker D. The $\alpha$ folate receptor is highly activated in malignant pleural mesothelioma. The Journal of thoracic and cardiovascular surgery. 2001; 121:225-233.

15. Despierre E, Lambrechts $\mathrm{S}$, Leunen $\mathrm{K}$, Berteloot $\mathrm{P}$, Neven P, Amant F, O'Shannessy DJ, Somers EB, Vergote I. Folate receptor alpha (FRA) expression remains unchanged in epithelial ovarian and endometrial cancer after chemotherapy. Gynecol Oncol. 2013; 130:192-199.

16. Kelemen LE. The role of folate receptor $\alpha$ in cancer development, progression and treatment: cause, consequence or innocent bystander? International journal of cancer. 2006; 119:243-250.

17. Kershaw MH, Westwood JA, Parker LL, Wang G, Eshhar Z, Mavroukakis SA, White DE, Wunderlich JR, Canevari S, Rogers-Freezer L. A phase I study on adoptive immunotherapy using gene-modified $\mathrm{T}$ cells for ovarian cancer. Clinical Cancer Research. 2006; 12:6106-6115.

18. Maus MV, Haas AR, Beatty GL, Albelda SM, Levine BL, Liu X, Zhao Y, Kalos M, June CH. T Cells Expressing Chimeric Antigen Receptors Can Cause Anaphylaxis in Humans. Cancer Immunology Research. 2013; 1:26-31.

19. Song D-G, Ye Q, Poussin M, Harms GM, Figini M, Powell DJ, Jr. CD27 costimulation augments the survival and antitumor activity of redirected human T cells in vivo. Blood. 2012; 119:696-706.

20. Song D-G, Ye Q, Carpenito C, Poussin M, Wang L-P, Ji C, Figini $\mathrm{M}$, June $\mathrm{CH}$, Coukos $\mathrm{G}$, Powell DJ. In vivo persistence, tumor localization, and antitumor activity of CARengineered $\mathrm{T}$ cells is enhanced by costimulatory signaling through CD137 (4-1BB). Cancer Res. 2011; 71:4617-4627.

21. Figini M, Obici L, Mezzanzanica D, Griffiths A, Colnaghi MI, Winter G, Canevari S. Panning phage antibody libraries on cells: isolation of human Fab fragments against ovarian carcinoma using guided selection. Cancer research. 1998; 58:991-996.

22. Milone MC, Fish JD, Carpenito C, Carroll RG, Binder GK, Teachey D, Samanta M, Lakhal M, Gloss B, DanetDesnoyers G. Chimeric receptors containing CD137 signal transduction domains mediate enhanced survival of $\mathrm{T}$ cells and increased antileukemic efficacy in vivo. Molecular Therapy. 2009; 17:1453-1464. 
23. Ye Q, Song D, Poussin M, Yamamoto T, Best A, Li C, Coukos G, Powell DJ. CD137 accurately identifies and enriches for naturally-occurring tumor-reactive $\mathrm{T}$ cells in tumor. Clinical Cancer Research. 2013. clincanres. 0945.2013.

24. Chmielewski M, Hombach A, Heuser C, Adams GP, Abken $\mathrm{H}$. T cell activation by antibody-like immunoreceptors: increase in affinity of the single-chain fragment domain above threshold does not increase $\mathrm{T}$ cell activation against antigen-positive target cells but decreases selectivity. J Immunol. 2004; 173:7647-7653.

25. Lanitis E, Poussin M, Hagemann IS, Coukos G, Sandaltzopoulos R, Scholler N, Powell DJ, Jr. Redirected antitumor activity of primary human lymphocytes transduced with a fully human anti-mesothelin chimeric receptor. Mol Ther. 2012; 20:633-643.

26. Morgan RA, Yang JC, Kitano M, Dudley ME, Laurencot CM, Rosenberg SA. Case report of a serious adverse event following the administration of T cells transduced with a chimeric antigen receptor recognizing ERBB2. Molecular Therapy. 2010; 18:843-851.

27. Kochenderfer JN, Dudley ME, Feldman SA, Wilson WH, Spaner DE, Maric I, Stetler-Stevenson M, Phan GQ, Hughes MS, Sherry RM. B-cell depletion and remissions of malignancy along with cytokine-associated toxicity in a clinical trial of anti-CD19 chimeric-antigen-receptor-transduced T cells. Blood. 2012; 119:2709-2720.

28. Lamers CH, Sleijfer S, Vulto AG, Kruit WH, Kliffen M, Debets R, Gratama JW, Stoter G, Oosterwijk E. Treatment of metastatic renal cell carcinoma with autologous T-lymphocytes genetically retargeted against carbonic anhydrase IX: first clinical experience. Journal of Clinical Oncology. 2006; 24:e20-e22.

29. Savoldo B, Ramos CA, Liu E, Mims MP, Keating MJ, Carrum G, Kamble RT, Bollard CM, Gee AP, Mei Z. CD28 costimulation improves expansion and persistence of chimeric antigen receptor-modified $\mathrm{T}$ cells in lymphoma patients. The Journal of clinical investigation. 2011; 121:1822.

30. Finney HM, Akbar AN, Lawson AD. Activation of resting human primary $\mathrm{T}$ cells with chimeric receptors: costimulation from CD28, inducible costimulator, CD134, and
CD137 in series with signals from the TCR $\zeta$ chain. The Journal of Immunology. 2004; 172:104-113.

31. Parry RV, Rumbley CA, Vandenberghe LH, June CH, Riley JL. CD28 and inducible costimulatory protein Src homology 2 binding domains show distinct regulation of phosphatidylinositol 3-kinase, Bcl-xL, and IL-2 expression in primary human CD4 T lymphocytes. The Journal of Immunology. 2003; 171:166-174.

32. Shen C-J, Yang Y-X, Han EQ, Cao N, Wang Y-F, Wang Y, Zhao Y-Y, Zhao L-M, Cui J, Gupta P. Chimeric antigen receptor containing ICOS signaling domain mediates specific and efficient antitumor effect of $\mathrm{T}$ cells against EGFRvIII expressing glioma. Journal of hematology \& oncology. 2013; 6:33.

33. Duong CP, Westwood JA, Yong CS, Murphy A, Devaud C, John LB, Darcy PK, Kershaw MH. Engineering T Cell Function Using Chimeric Antigen Receptors Identified Using a DNA Library Approach. PLoS One. 2013; 8:e63037.

34. James SE, Greenberg PD, Jensen MC, Lin Y, Wang J, Budde LE, Till BG, Raubitschek AA, Forman SJ, Press OW. Mathematical modeling of chimeric TCR triggering predicts the magnitude of target lysis and its impairment by TCR downmodulation. The Journal of Immunology. 2010; 184:4284-4294.

35. Johnson LA, Morgan RA, Dudley ME, Cassard L, Yang JC, Hughes MS, Kammula US, Royal RE, Sherry RM, Wunderlich JR. Gene therapy with human and mouse T-cell receptors mediates cancer regression and targets normal tissues expressing cognate antigen. Blood. 2009; 114:535-546.

36. Lamers $\mathrm{CH}$, Langeveld SC, Groot-van Ruijven CM, Debets R, Sleijfer S, Gratama JW. Gene-modified T cells for adoptive immunotherapy of renal cell cancer maintain transgene-specific immune functions in vivo. Cancer Immunology, Immunotherapy. 2007; 56:1875-1883.

37. Lamers $\mathrm{CH}$, Willemsen $\mathrm{R}$, van Elzakker $\mathrm{P}$, van Steenbergen-Langeveld S, Broertjes M, OosterwijkWakka J, Oosterwijk E, Sleijfer S, Debets R, Gratama JW. Immune responses to transgene and retroviral vector in patients treated with ex vivo-engineered T cells. Blood. $2011 ; 117: 72-82$. 